\title{
O fortalecimento da democracia na América Latina em tempos de crise dos sistemas representativos
}

\author{
Victor Augusto Ramos Missiato ${ }^{1}$
}

CARVALHO E SILVA, R. F. de. A transformação da esquerda latino-americana: um estudo comparado do Partido dos Trabalhadores (PT) no Brasil e do Partido Socialista (PSCh) no Chile. João Pessoa: Editora UFPB, 2013, 360 p.

Resenha recebida em: 05/08/2014

Resenha aprovada para publicação em: 19/11/2014

A partir do final da década de 1970, diversos partidos e movimentos da esquerda latino-americana iniciaram um processo de transformação conceitual, política e estratégica no que tange às suas concepções e relações propriamente práticas com a democracia política. De início, como oposição aos regimes ditatoriais e, em seguida, como partícipes dos processos de redemocratização que dariam legitimidade à nova ordem democrática instaurada, em sua maioria, no decorrer dos anos 1980. Parte fundamental dessa mudança encontra-se na atual interação com os sistemas políticos vigentes em vários países da região, onde tais partidos têm como grande meta a vitória nas eleições e, uma vez vitoriosos, a instituição de suas propostas programáticas, mediante alianças decorrentes da institucionalização do partido no sistema político nacional. Imersa nessa questão encontra-se a temática do livro A transformação da esquerda latino-americana: um estudo comparado do Partido dos Trabalhadores (PT) no Brasil e do Partido Socialista (PSCh) no Chile, de Rodrigo Freire de Carvalho e Silva, professor do Departamento de Ciências Sociais da Universidade Federal da Paraíba (UFPB). Seu principal objetivo é traçar "um estudo de um tipo específico da

\footnotetext{
${ }^{1}$ Doutorando em História pela FCHS-UNESP, Brasil. Atualmente, desenvolve uma pesquisa intitulada $A$ esquerda latino-americana antes e depois da Revolução Cubana de 1959: um estudo comparativo sobre os comunistas no Brasil e no Chile. E-mail: victor_missiato@ hotmail.com.
}

\section{CANPHLAC}

Revista Eletrônica da ANPHLAC, ISSN 1679-1061, Nº. 17, p. 368-373, jul./dez. 2014. http://revista.anphlac.org.br/ 
esquerda latino-americana contemporânea: a esquerda reformista social-democrática" (p. 15). O autor, apesar de destacar em sua Introdução, a título de exemplo, outras experiências latino-americanas, como as correntes frentistas de Uruguai e El Salvador, concentrará sua pesquisa nos casos de PT e PSCh, por serem "conceitualmente caracterizados como partidos políticos”, a partir das caracterizações empreendidas por autores como Moisei Ostrogorski, Max Weber e Robert Michels (p. 16).

O livro de Rodrigo Freire pode ser dividido em uma extensa parte que percorre a construção do conceito de partido político na ciência política contemporânea (capítulo 1); a análise dos sistemas partidários de Brasil e Chile (capítulo 2); as relações entre democracia e globalização no mundo contemporâneo (capítulo 3) e as transformações da esquerda latino-americana nessa conjuntura política (capítulo 4), sendo os últimos dois capítulos destinados aos estudos do PSCh e do PT. Embora necessário, a fim de situar os partidos analisados dentro de um processo global de transformações sociais e políticas nos últimos 40 anos, o debate explorado no livro, a nosso ver, obteve um espaço demasiado significativo, em detrimento de uma análise comparativa entre os dois partidos. Ao invés de realizar um "estudo comparado" em profundidade, Rodrigo Freire acabou por analisar o histórico e a atual relação desses partidos políticos com os sistemas políticos de seus respectivos países, sendo que o objetivo de realizar um estudo comparativo ficou em segundo plano ao longo do trabalho.

Ao focarmos a questão comparativa do texto, no capítulo 2, destacamos que Rodrigo Freire buscou analisar os sistemas partidários de Chile e Brasil. Segundo ele, o sistema partidário "é um elemento central dos sistemas políticos democráticos", pois “organiza o padrão de competição política” (p. 53). Quanto à relação histórica entre sistema partidário e democracia, o autor destaca a "estabilidade democrática" chilena durante quase todo o século XX (p. 56), ao contrário do sistema partidário brasileiro, considerado frágil ao longo dessa mesma época, mas que, na visão do autor, atualmente, caminha para "uma democracia que está em vias de institucionalização" (p. 92). Contudo, ao longo das análises elaboradas por Rodrigo Freire, é possível perceber outra distinção entre esses dois sistemas partidários, dessa vez mais contemporânea. No Chile, apesar da vitória do "NO", no plebiscito de 1988, que resultou no fim do governo ditatorial de Pinochet (1973-1990), a Constituição de 1980, formulada durante a

\section{GANPHLAC}

Revista Eletrônica da ANPHLAC, ISSN 1679-1061, No. 17, p. 368-373, jul./dez. 2014. http://revista.anphlac.org.br/ 
ditadura, manteve-se vigente após a redemocratização. No Brasil, apesar de haver também uma "transição pactuada" entre militares e civis, houve a elaboração de um processo constituinte que resultou em uma Constituição mais identificada com os novos tempos democráticos (p. 68). Portanto, a análise acerca desses dois sistemas partidários não é linear-evolutiva e possibilita visualizar diferentes níveis de desenvolvimento a partir de momentos históricos distintos.

Uma outra importante contribuição do livro, que repara, em parte, a pouca sistematização comparativa entre os dois partidos, está na sutil conexão estabelecida entre os processos políticos democráticos latino-americanos e os objetos de estudo (no caso, PT e PSCh), quando, no decorrer do texto, o autor aborda "o recente movimento histórico de "reconciliação" da maior parte da esquerda mundial com a tradição democrática do liberalismo político" (p. 96). Foi a partir dessa conjuntura de crítica ao marxismo bolchevique e à chegada de novas leituras de esquerda na América Latina que o caráter instrumental de democracia cede espaço ao seu caráter universal:

\begin{abstract}
A partir de então, a democracia - incorporando conceitualmente o rol de direitos da tradição do liberalismo político - passa a ocupar papel central no projeto da esquerda. No caso da América do Sul, entretanto, esta reconciliação inicia antes: desde o processo de transição à democracia como parte da sua estratégia socialista. Democracia não é mais entendida como um "meio" para se atingir o socialismo, mas parte fundamental da ideia de socialismo sustentada por esta esquerda, da qual o PT e o PS do Chile são alguns dos representantes mais legítimos na América Latina [...] (p. 97).
\end{abstract}

Todavia, os limites dessa argumentação encontram-se tanto no plano das interpretações teóricas feitas pelo autor como na prática político-partidária. Conforme nossa interpretação, em relação ao debate teórico, durante a década de 1980, visualizamos que essas correntes não incorporaram a democracia liberal no centro de seus projetos. Vinculada à concepção de democratização social, que permeou o ideário dessa "nova esquerda", apontada pelo autor, há sim uma aproximação entre socialismo e democracia, mas não nos moldes do liberalismo político. Segundo essa concepção, a realização plena da democracia só poderia ocorrer em um regime socialista. Ao perceber a democracia como um processo, ela estaria desassociada das formas

\title{
GANPHLAC
}

Revista Eletrônica da ANPHLAC, ISSN 1679-1061, Nº. 17, p. 368-373, jul./dez. 2014. http://revista.anphlac.org.br/ 
institucionais que assume em determinados contextos históricos, e sua existência só seria possível com o socialismo, da mesma forma que o socialismo só se constituiria vinculado à democracia com igual ênfase. Na matriz teórica desse pensamento, é possível perceber muito mais a influência de um Lukács e/ou de um Lenin do que uma grande relação "com a tradição democrática do liberalismo político". Essa foi uma das bases teóricas que migraram e auxiliaram na formação do Partido dos Trabalhadores, em 1980, e estiveram presentes no PSCh, durante a década de 1980.

No plano político-partidário, esses limites também se encontrariam presentes, especialmente no partido brasileiro. Nesse momento, destacamos que o PT atuou como crítico da redemocratização empreendida pelo Movimento Democrático Brasileiro (MDB). Entre outras questões, o Partido dos Trabalhadores, apesar de assinar a Constituição de 1988, não a assumiu como um legado democrático para a sociedade brasileira daquele período, embora reconheça a sua grande importância nos dias de hoje. Portanto, à margem das transformações democráticas daquele período, que não ocorreram sem percalços e resquícios autoritários, no plano político-institucional, o PT também não esteve ligado a essa tradição liberal-democrática, ao contrário do que afirma Rodrigo Freire. Em comparação com os Socialistas chilenos, que conseguiram um pacto com outras forças políticas e assumiram um papel de maior destaque na redemocratização em seu país, o PT iria passar por algumas experiências até se converter, também em parte, a essa linha. No entanto, seu papel extrainstitucional nos anos 1980 como partido representante de grupos sociais subalternos o credencia, também, como partícipe do processo de redemocratização no Brasil, embora de maneira tangencial no que se refere à sua participação no legado institucional da redemocratização brasileira. Enquanto isso, o PSCh, em comparação com o PT, participou da Alianza Democrática, que arregimentou partidos da esquerda, de centro (em especial, a Democracia Cristã) e até o Partido Liberal, considerado de "direita" pelo autor (p. 190). Portanto, no plano político-partidário e sua relação com a democracia liberal, ao final da década de 1980, consideramos que o PSCh teve uma estratégia política distinta da estratégia petista, aproximando-se mais da democracia liberal institucional, o que pode ter sido um dos fatores da vitória nas eleições presidenciais de 1989.

\section{GANPHLAC}

Revista Eletrônica da ANPHLAC, ISSN 1679-1061, Nº. 17, p. 368-373, jul./dez. 2014. http://revista.anphlac.org.br/ 
Nos capítulos finais (5 e 6), Rodrigo Freire traça os diferentes caminhos percorridos pelos dois partidos no século XX, que culminaram em um mesmo ponto de chegada: a "via reformista social-democrática latino-americana". Afora os distintos períodos históricos de suas formações e os diferentes grupos sociais que compuseram seus quadros, uma mesma problemática influenciou na atual concepção políticoestratégica dos dois partidos: uma resposta ao sistema autoritário em que Brasil e Chile estiveram imersos nas décadas de 1970 e 1980. Embora certeira, a maneira como o autor constrói sua argumentação, quando se busca resgatar uma tradição democrática do PS, a partir do seu início, tentando demonstrar que sua atuação nos anos 1960-1970 foi um "interstício", acaba por comprometê-la. Ao utilizar um historiador de filiação socialista (Jorge Arrate), Rodrigo Freire se equivoca ao defender uma tradição democrática do socialismo chileno, que foi abandonada pela maior parte de seus militantes, em 1967, e depois voltou a hegemonizar sua estratégia (p. 189). Na década de 1930, as esquerdas visualizavam a democracia como um sentido etapista para o processo revolucionário socialista. Portanto, ao contrário de um interstício, as influências maoístas, guevaristas e/ou leninistas da década de 1960 apenas reforçaram e reformaram àquele pensamento da década de 1930.

Embora outros questionamentos possam ser feitos em relação a alguns conceitos ou concepções políticas referentes às trajetórias desses dois partidos e suas relações com as culturas políticas nacionais, destacamos, por fim, a importância desse estudo sobre os partidos políticos para a democracia representativa em tempos de crise e questionamentos desse sistema. Se entre os anos 2009-2012, algumas vozes da esquerda (Zizek, Safatle, R. Jacoby, entre outros intelectuais), críticas à democracia representativa, tenham decretado o esgotamento de seu sistema político e das instituições democrático-liberais, em detrimento de um "neoliberalismo" que diluiu os ganhos empreendidos pelo Estado de Bem-Estar Social, comumente associado ao período 1930-1980, a obra de Rodrigo Freire aponta para um processo de construção e fortalecimento desse sistema na América Latina, mesmo considerando a conjuntura de crise que esse modelo enfrenta. Portanto, a partir da leitura dessa obra, corroboramos com a tese de que, a partir do aprofundamento do atual sistema representativo, a democracia se fortaleceu na região. Em sintonia com essa perspectiva, visualizamos o

\section{GANPHLAC}

Revista Eletrônica da ANPHLAC, ISSN 1679-1061, Nº. 17, p. 368-373, jul./dez. 2014. http://revista.anphlac.org.br/ 
atual debate sobre a formulação de uma nova Constituição no Chile, a ser redigida em tempos democráticos, e o debate no Brasil acerca da relação dos Três Poderes e seus avanços e limites no desenvolvimento da cidadania no país como ações que podem reformar e fortalecer a cultura política democrática na América Latina.

\section{CANPHLAC}

Revista Eletrônica da ANPHLAC, ISSN 1679-1061, Nº. 17, p. 368-373, jul./dez. 2014.

http://revista.anphlac.org.br/ 